\title{
Maximising Discharge Burnup in an Open Cycle Molten Salt Reactor
}

\author{
Charlie Constable $^{1}$, Dr Ben Lindley ${ }^{2}$, and Dr Geoff Parks ${ }^{1}$ \\ ${ }^{1}$ Cambridge University Engineering Department \\ Trumpington Street, Cambridge, CB2 1PZ, United Kingdom \\ ${ }^{2}$ Wood \\ Kings Point House, Queen Mother Square, Dorchester, DT1 3BW, United Kingdom \\ cc846@cam.ac.uk, ben.lindley@woodplc.com,gtp10@cam.ac.uk
}

\begin{abstract}
This paper discusses work done to find an estimate of the maximum achievable discharge burnup in an open cycle molten salt reactor (MSR). An in-development deterministic code (WIMS11) is used to create a model of a simple generic MSR, and the methodology employed is discussed. Some experimentation is done with regards to the internal set-up of the 'unit cells' within the core, which shows there is a strong link between this geometry and the achievable burnup. Work is done to quantify the effects of removing volatile fission products and implementing a two-batch refuelling scheme. Finally, an optimisation process is carried out whereby the optimal proportion of graphite moderator within the core is found which balances power across the regions while maximising discharge burnup. Two fuels are tested, one which carries only ${ }^{235} \mathrm{U}$ and ${ }^{238} \mathrm{U}$, and another which also carries ${ }^{232} \mathrm{Th}$. It is found that the maximum achievable discharge burnup is approximately $155 \mathrm{MWd} / \mathrm{kg}$, which is considerably higher than modern PWRs, despite a lower enrichment and only two batches of fuel being used.
\end{abstract}

KEYWORDS: Molten Salt, WIMS, Burnup, Multibatch, Spectral Shift

\section{INTRODUCTION}

This paper describes an exercise for a generic molten salt reactor (MSR) design, utilising the deterministic reactor physics code WIMS11. The exercise aims to provide estimates of the possible discharge burnup within a generic proposed MSR design. The limitations of this work are also discussed. Previous research has indicated that an MSR with a low enrichment of fissile heavy metals is an area of interest for next generation nuclear reactors, due to their low requirements for online reprocessing and good proliferation hardness [1]. This has led to the development of a basic WIMS model of such an MSR in Cambridge [2]. This paper extends this model, in order to understand if this type of MSR can compete with a modern reactor in terms of discharge burnup.

In the past few years, many papers have been published on this topic from a variety of institutions from around the world. A few works of particular interest to this paper are set out below. Research investigating the effect of through lifetime spectral shift within a core was recently published by 
the Oak Ridge National Laboratory [3]. That paper showed that significant volumes of ${ }^{239} \mathrm{Pu}$ can be bred early in the cycle, which is then burnt later on when the spectrum is softened, indicating a potential improvement in discharge burnup to $91.9 \mathrm{GWD} / \mathrm{MTU}$. Recent research by the University of Illinois has also investigated the effects of different fuel reprocessing schemes [4].

\section{DESCRIPTION OF WIMS MODEL}

Initially, the code performs a number of one-off calculations and processing. The geometry of the core is calculated based on a constant volume of fuel, and input proportions of graphite in the inner and outer regions of the core. The volume of fuel in the inner and outer regions is equal, due to the need to move the fuel from the inner to the outer region to effect a two-batch refuelling scheme.

The main body of the code then exists in a large loop. In this section of the code, a calculation is done for the unit cells in both the inner and outer regions of the core. This provides information on the infinite multiplication factor of these regions of the core. This information is then condensed from 172 energy groups to 22, to increase the speed of computation. The MERLIN module then completes a full RZ calculation of the core using the SP3 method, the geometry of which is shown in Fig. 1. This provides information on the reactivity of the core. If the core is not at the end of cycle, the code then uses the BURNUP module to predict the production of fission products and changes in inventories of other isotopes. If the calculation done is for the end of a cycle, then this section also moves the inner fuel to the outer region and refuels the inner region with fresh fuel. In the first cycle the entire core was 'fuelled' with fresh salt and a number of cycles then modelled until equilibrium was found, allowing the fuel cycle transients to die away. Through methods such as changing enrichment, an initial fuel for the outer region could be produced which would allow near equilibrium operation in cycle one.
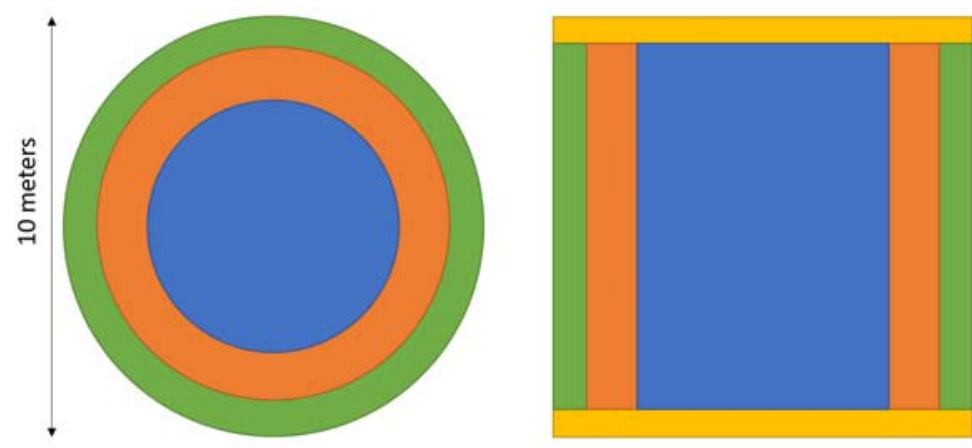

\footnotetext{
- Core Inner Region

- Core Outer Region

- Graphite Reflector

a Hastalloy Reflector
}

Figure 1: RZ model passed to MERLIN

Finally, the general method of optimisation needs to be outlined. A number of outer region graphite compositions were selected. For each, the inner graphite composition and cycle length were then varied, so as to maximise the equilibrium cycle length while balancing burnup between the two regions in an effort to ensure approximately balanced power output across the reactor. A limit was also imposed on the precision of the length of cycles being a multiple of 0.05 years long. The burnup between regions was deemed balanced if there was less than a 5\% difference between the inner and outer regions. 


\section{UNIT CELL INVESTIGATION}

The first investigation carried out sought the best arrangement of fuel salt and graphite within the unit cell. Initially, the code had used a hexagonal unit cell containing a ring of graphite. Salt then existed in the gaps between these rings and in the hollow cavity inside the ring. The effect from changing the size of the unit cell was not investigated, but there are other geometries within the unit cell available which would allow the same proportion of graphite to be realised. These different proposed designs are shown in Fig. 2, and each contains the same proportion of graphite.

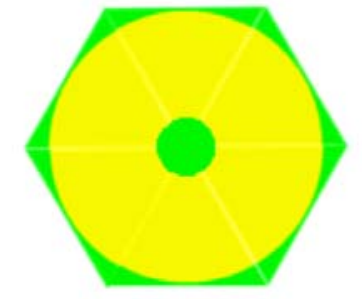

a: Original Unit Cell

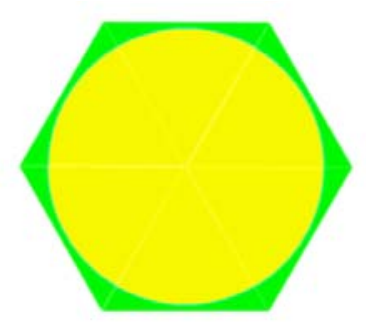

b: Solid Unit Cell

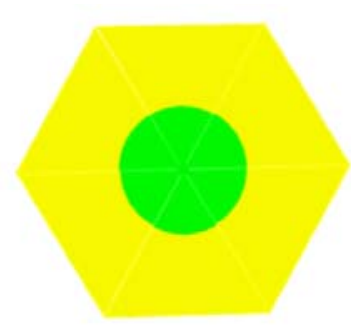

c: Hollow Unit Cell

\section{Figure 2: Investigated unit cells (yellow - graphite, green - fuel salt)}

In order to investigate how these different unit cell geometries affect the operation of the reactor, a one-year two-batch cycle was modelled with each unit cell type. The results of this modelling are shown in Fig. 3. Each test had the same proportions of graphite in the inner and outer regions, and thorium-rich fuel was used in this test.

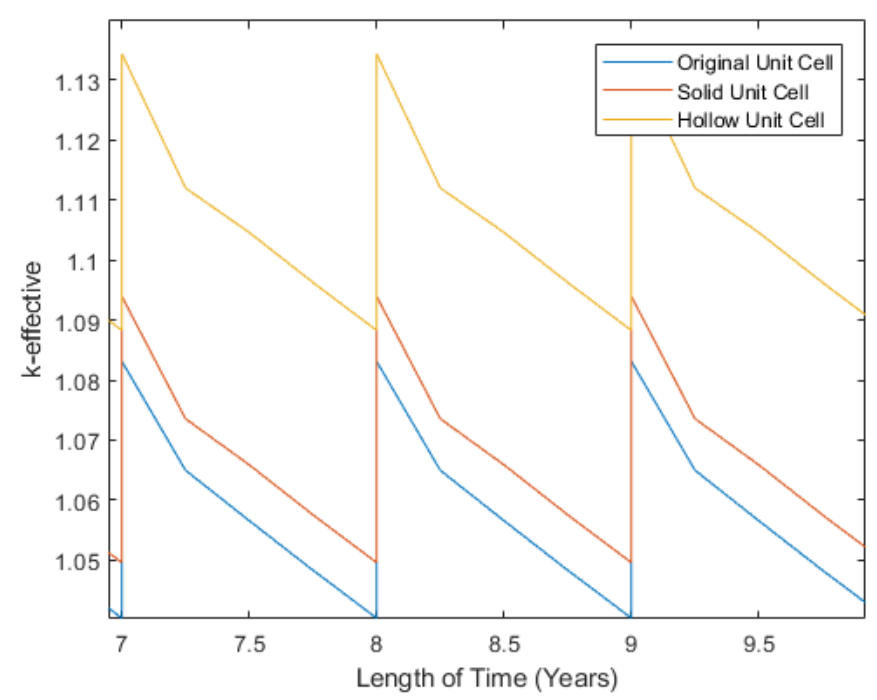

Figure 3: Criticality of core through cycle for each unit cell

It can be seen that both the solid and hollow unit cells yield a higher k-effective than the original geometry. This allows a longer cycle length before k-effective drops below one, thus allowing a greater burnup of the fuel at constant power. This increase is due to the moderator being more clumped together, which increases the number of neutrons reaching thermal energies. This is be- 
cause there is a greater likelihood of neutrons reaching the thermal region without coming into contact with fuel and being absorbed in the epithermal region. British Advanced Gas-cooled Reactors (AGRs) used a similar methodology, where fuel and graphite was clumped together [5]. However, the very large improvements in the modelled MSR due to the hollow geometry were unexpected. Although certain improvements in the accuracy of the model do decrease the predicted criticality, the decrease is much smaller than the difference between the hollow and original model (the majority of improvements caused no discernible difference). It therefore appears that this is a physical effect. Following this investigation, the MONK Monte Carlo code [6] was used to model the different unit cells, which confirmed a significantly higher criticality in the hollow case, the results of which are seen in Table I. The physicality of this effect is therefore very strongly supported, as two different codes using different calculational routes have both predicted its existence. Accordingly, the hollow unit cell is selected as it promises the best performance.

Table I: Infinite multiplication factor for different unit cells

\begin{tabular}{|c|c|c|}
\hline Unit Cell & MONK & WIMS \\
\hline Solid & $1.1465 \pm 0.0004$ & 1.139234 \\
\hline Hollow & $1.1780 \pm 0.0004$ & 1.179777 \\
\hline
\end{tabular}

\section{PRELIMINARY INVESTIGATIONS}

A number of investigations were then carried out to explore the expected burnup from the proposed MSR. Two main effects were investigated: the use of a two-batch cycle, and the effects of continuously removing volatile fission products. In many proposed MSRs volatile fission products are constantly removed, for instance by bubbling helium through the core (see [7]). The code simulates this by removing these isotopes each time a burnup calculation is executed. The two-batch scheme operates by having two moving circuits, with one third of the fuel not in residence in the core. At refuelling, the inner region fuel is moved fully to the outer region. A one-batch scheme can also be investigated with no changes to the code by considering the first cycle, where all the fuel in the core is fresh, but mixing between the two regions could not be modelled by this method.

Therefore, a process was undertaken where the core cycle length was maximised while balancing the burnup by varying the inner proportion of graphite. Balancing occurred due to the neutron spectrum being hardened by a decrease in the proportion of moderator. As this drops, more neutrons are used to breed fissile fuel and fewer to cause fissions. This scheme was implemented for both one- and two-batch schemes, with and without volatile fission products being removed. The hollow unit cell was used, as the previous section identified this as offering the highest burnups, and a thorium-rich fuel was also used. The results of this modelling are shown in Table II.

It is clear from Table II that the removal of fission products is causing a large improvement to potential burnup, improving the performance of the reactor by $134 \%$ in the two-batch scheme. This improvement in discharge burnup is well worth the added complexity of a system to remove the volatile fission products, and so all following simulations include the removal of fission products. It can also be seen that the implementation of a two-batch scheme improves the discharge burnup by approximately $78 \%$. These results can then be compared to linear reactivity model predictions. 
Table II: Preliminary multibatch modelling results

\begin{tabular}{|c|c|c|c|c|}
\hline $\begin{array}{c}\text { Fission } \\
\text { Products }\end{array}$ & $\begin{array}{c}\text { Number of } \\
\text { Batches }\end{array}$ & $\begin{array}{c}\text { Cycle Length } \\
\text { (years) }\end{array}$ & $\begin{array}{c}\text { Residence Time } \\
\text { (years) }\end{array}$ & $\begin{array}{c}\text { Discharge Burnup } \\
\text { GWd/tonne }\end{array}$ \\
\hline Retained & One & 4.15 & 4.15 & 24.0 \\
\hline Retained & Two & 3.10 & 6.20 & 35.7 \\
\hline Removed & One & 8.10 & 8.10 & 47.1 \\
\hline Removed & Two & 7.20 & 14.40 & 83.7 \\
\hline
\end{tabular}

For the case with fission products removed, the linear reactivity model predicted a discharge burnup of $62.8 \mathrm{GWd}$ /tonne and a cycle length of 5.4 years. The model has significantly outperformed these expectations, and this is attributed to the effects of spectral shift due to different spectrums in each region. As the fuel is resident in the core for a longer period of time, more fissile ${ }^{233} \mathrm{U}$ can be bred in the central region with a harder spectrum, before being burnt in the outer region with a more thermal spectrum. This allows the reactor to stay critical for longer, hence increasing the cycle length and the discharge burnup.

These values can be compared to discharge burnup in a PWR. Maximum economic burnup in a PWR is estimated to be around $100 \mathrm{GWd}$ /tonne [8], while, more typically, burnups in the region of $50-60 \mathrm{GWd}$ /tonne are achieved [9]. This is because the length of time fuel can be burnt in a PWR is normally limited by damage to the fuel cladding; this is not a factor in an MSR as there is no fuel cladding. Therefore, it can be seen that the proposed MSR competes with modern PWRs in terms of discharge burnup, despite a much lower initial enrichment. The next sections in this paper seek to investigate further effects and consider if this discharge burnup can be increased further.

\section{CYCLE AND FUEL OPTIMISATION}

The next investigation considered how to maximise the discharge burnup by varying the graphite proportions in the reactor. The burnup depends upon the core residence time, the power of the reactor and the initial heavy metal inventory of the core. As the power and the heavy metal inventory are constant at different graphite proportions, maximising the cycle length also maximises the burnup. The optimisation was carried out by considering a number of outer region graphite proportions, and then maximising the cycle length while varying the inner graphite proportions in order to balance the burnup in each region.

In much academic research, the MSR is seen as one route of entry to the thorium fuel cycle. These fuels require an initial proportion of ${ }^{235} \mathrm{U}$ to produce neutrons to breed ${ }^{233} \mathrm{U}$ from ${ }^{232} \mathrm{Th}$, which can ultimately become self-sustaining and remove the requirement for ${ }^{235} \mathrm{U}$. There are a number of advantages to this approach, such as potentially significantly shorter radioactive waste lifetimes and a much greater availability of fuel [10]. However, other research does consider whether purely uranium fuelled MSRs, in which fissile ${ }^{239} \mathrm{Pu}$ is bred from ${ }^{238} \mathrm{U}$, might also operate effectively [11]. Therefore, it was decided to carry out another optimisation using a fuel salt carrying only uranium and no thorium. In order to do this, it was important to ensure the fuel salt modelled was chemically compatible. A number of proposals exist for fuel salts, such as ones with no lithium 
Table III: Atomic densities of thorium \& uranium fuels given in units of atoms/barn cm

\begin{tabular}{|c|c|c|}
\hline Isotope $\backslash$ Material & Thorium Fuelled Salt & Uranium Fuelled Salt \\
\hline${ }^{N a t} \mathrm{H}$ & $1.000 \mathrm{E}-19$ & $1.000 \mathrm{E}-19$ \\
\hline${ }^{7} \mathrm{Li}$ & $2.303 \mathrm{E}-02$ & $2.063 \mathrm{E}-02$ \\
\hline${ }^{\mathrm{Nat}} \mathrm{Be}$ & $5.134 \mathrm{E}-03$ & $1.041 \mathrm{E}-02$ \\
\hline${ }^{\mathrm{Nat}} \mathrm{C}$ & $1.000 \mathrm{E}-19$ & $1.000 \mathrm{E}-19$ \\
\hline${ }^{\mathrm{Nat}} \mathrm{N}$ & $1.000 \mathrm{E}-19$ & $1.000 \mathrm{E}-19$ \\
\hline${ }^{\mathrm{Nat}} \mathrm{F}$ & $4.512 \mathrm{E}-02$ & $4.976 \mathrm{E}-02$ \\
\hline${ }^{232} \mathrm{Th}$ & $2.559 \mathrm{E}-03$ & - \\
\hline${ }^{235} \mathrm{U}$ & $7.920 \mathrm{E}-05$ & $7.920 \mathrm{E}-05$ \\
\hline${ }^{238} \mathrm{U}$ & $3.175 \mathrm{E}-04$ & $2.813 \mathrm{E}-03$ \\
\hline
\end{tabular}

or beryllium content [11]. However, for a fair comparison with the thorium-rich fuel, the fuel salt from the MSRE was modified for this fuel (see [12]). The composition of the two compared fuels are shown in Table III.

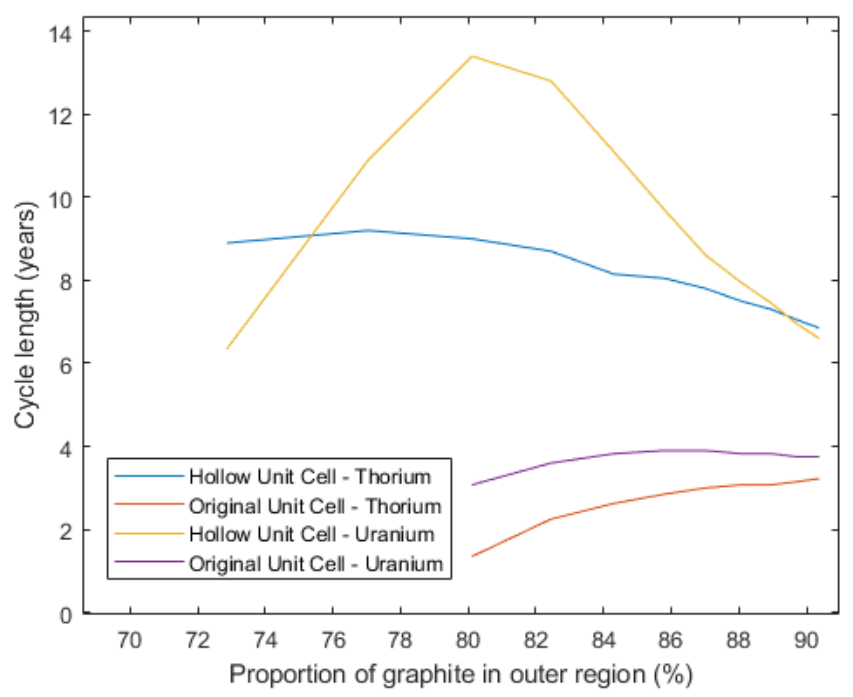

Figure 4: Maximum cycle length at various outer graphite proportions with uranium or thorium fuel

It is clear from Fig. 4 that the uranium fuelled MSR offers even greater cycle lengths and hence greater burnup. One possible explanation would be that the thorium fuel contained both ${ }^{232} \mathrm{Th}$ and ${ }^{238} \mathrm{U}$, and so more regions of resonance absorption had to be passed through before neutrons were thermalised. This would increase the proportion of neutrons absorbed rather than causing fission, decreasing the reactivity of the core. This effect could explain the better breeding performance of the purely uranium fuel for this configuration of reactor. 
There are, of course, other relevant factors besides the discharge burnup when designing reactors. One major consideration is the size of the reactor: smaller reactors require smaller containment structures and are therefore cheaper. As the volume of fuel salt in each region is fixed, the volume of the graphite must increase to increase the volume fraction of graphite. Therefore, the volume of the entire reactor must increase to allow this. The height of the reactor is fixed, and so the radius of the reactor changes to account for the change in volume of the core. The trace of the radius against the outer core proportion of graphite is shown in Fig. 5. It is clear that reactors with smaller graphite proportions decrease the radius of the core, which should contribute to lower costs. It is also interesting to note here that the original unit cell requires higher inner graphite proportions to balance the power of the reactor, contributing to higher core radii. As the burnup is maximised at much lower graphite proportions with the hollow unit cell, a much smaller core radius is required, again showing the benefits of this geometry.

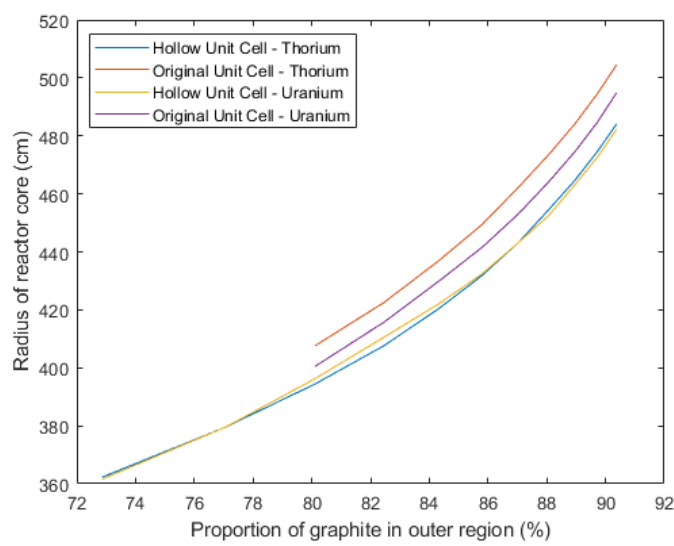

Figure 5: Radii of modelled cores

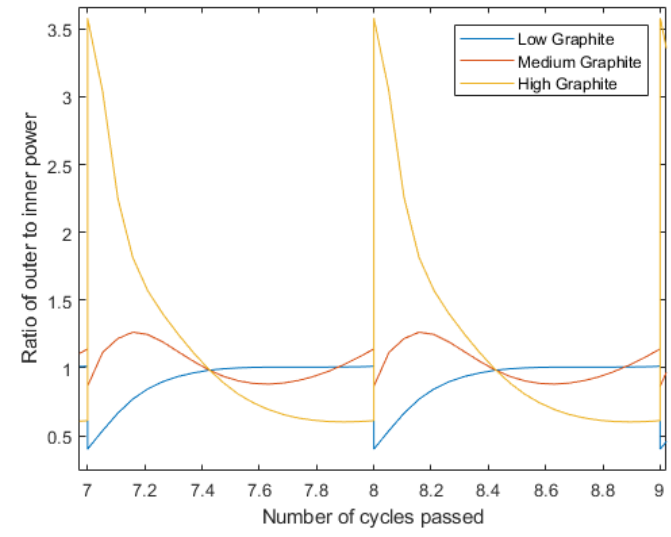

Figure 6: Ratio of powers: inner to outer region

Another design consideration is that of power balancing through the cycle. The optimisation constraint used was that, at the end of cycle, the burnup in each region of the core would be the same. However, it is possible that there would be great variation in the power balance during the cycle, and this is worthy of investigation. The ratio of the powers is used to indicate the power balance between the regions. In a fully balanced reactor (where each region produced the same power) this ratio would remain at one throughout the cycle. Fig. 6 shows this power balance through cycle for the highest burnup set-up - purely uranium fuel and hollow unit cell. Only the highest, median and lowest graphite concentrations have been displayed to aid clarity. It is clear from these figures that the power is not balanced throughout the cycle and further work would be required to maintain this balancing at all times.

\section{CONCLUSIONS}

This study focused on maximising the discharge burnup of a generic model of an MSR using WIMS. This research allowed a preliminary assessment regarding the predicted design point with maximum discharge burnup. This design used the 'hollow' unit cell, fuel which contained only ${ }^{235} \mathrm{U} \&{ }^{238} \mathrm{U}$ at an enrichment of $2.7 \%$, and had graphite proportions of $80 \%$ and $73 \%$ by volume in the outer and inner regions respectively. This core indicated a discharge burnup of 155 $\mathrm{MWd} / \mathrm{kg}$ when using a two-batch refuelling scheme. This is a very high discharge burnup, typical 
current light water reactors have a discharge burnup of $50 \mathrm{MWd} / \mathrm{kg}$ [8], which suggests that this design could be very advantageous from a fuel economy point of view. The effect of removing the spectral shift was investigated by having a constant graphite proportion throughout, and at the optimal graphite proportion, showed a drop in discharge burnup of $31 \%$. Smaller investigations were also made into changing to a one-batch scheme and into not removing volatile fission products. These indicated a drop in discharge burnup of $44 \%$ and $57 \%$, respectively, when these effects were removed. WIMS11's introduction also provides some opportunities for the development of the model to include further effects. For instance, there is currently no thermal-hydraulic model included, but this is expected to be part of the final version.

\section{ACKNOWLEDGEMENTS}

The authors would like to thank Andy Whyte (current CUED PhD student) for his help with postprocessing information from WIMS.

\section{REFERENCES}

[1] K. Trinh, Options for Improving Fuel Utilisation in the Denatured Molten Salt Reactor, University of Cambridge, $\mathrm{PhD}$ Thesis (2016)

[2] F. Hall, Reactor Physics Modelling of Molten Salt Reactors, University of Cambridge, MPhil Dissertation (2018)

[3] B. R. Betzler et al., "Fuel Cycle and Neutronic Performance of a Spectral Shift Molten Salt Reactor Design", Annals of Nuclear Energy, 119, pp. 396-410 (2018)

[4] A. Rykhlevskii, J. W. Bae and K. D. Huff, "Modelling and Simulation of Online Reprocessing in the Thorium-Fueled Molten Salt Breeder Reactor", Annals of Nuclear Energy, 128, pp. 366-379 (2019)

[5] E. Nonbel, Description of the Advanced Gas Cooled Type of Reactor (AGR), pp. 23, Riso National Laboratory, Roskilde, Denmark (1996)

[6] D. Long et al., "MONK10: A Monte Carlo Code for Criticality Analysis", ICNC 2015, Charlotte, USA, 13-17 September (2015)

[7] D. LeBlanc, "Molten Salt Reactors: A new beginning for an old idea," Nuclear Engineering and Design, 240, pp. 1644-1656 (2010)

[8] Nuclear Energy Agency, Very High Burn-ups in Light Water Reactors, pp. 119, OECD, Paris, France (2006)

[9] L. P. Tucker and S. Usman, "Thorium-Based Mixed Oxide Fuel in a Pressurized Water Reactor: A Burnup Analysis with MCNP”, Annals of Nuclear Energy, 111, pp. 163-175 (2018)

[10] R. F. Hargraves and R. Moir, "Liquid Fluoride Thorium Reactors", American Scientist, 98, pp. 304-313 (2010)

[11] D. Moser, A. Wheeler and O. Chvla, "Lattice optimization for graphite moderated molten salt reactors using low-enriched uranium fuel", Annals of Nuclear Energy, 110, pp. 1-10 (2017)

[12] B. I. Prince, S. J. Ball, J. R. Engel, P. N. Haubenreich and T. W. Kerlin, Zero-Power Physics Experiments On The Molten-Salt Reactor Experiment, Oak Ridge National Laboratory, United States of America (1968) 